\title{
Internal Root Resorption: Should we Change our Vision?
}

\author{
Robledo JG \\ Department of Operative and Prosthodontic, School of Dentistry, Argentina \\ *Corresponding author: Robledo JG, Endodontist, Department of Operative and Prosthodontics, School of Dentistry, Argentina
}

Submission: 攸 November 23, 2018; Published: 㭗 December 11, 2018

\begin{abstract}
Internal Root Resorption is usually asymptomatic. Manifest itself under pathologic conditions and requires vital pulp tissue for their development. Etiologic factors such as trauma, inflammation, caries, restorative procedures have been suggested. If the lesion is detected early and of small size, the prognosis is favorable. Studies revealed that resorptive process in teeth is comparable to bone resorption. Cleaning and shaping with hand-files/rotary instruments, irrigants, ultrasonic instrumentation and calcium hydroxide are considered essential for arresting the resorptive activity. However, exists a big challenge due to the heterogeneity of pulpal space and creation of a conductive habitat to the healing of supporting tissues.
\end{abstract}

Abbreviations: Internal root resorption; Endodontics; Osteoclast/odontoclast activity

\section{Introduction}

Supposedly, Broomell in 1898, was the first person in using the term "resorption" [1]. As stated by the Glossary of the American Association of Endodontists, internal resorption is defined as an inflammatory process initiated within the pulp space with loss of dentin and possible invasion of the cementum [2]. Frequently, is found in the cervical region; however, it can take place in all areas of the root canal system. Trauma, bacterial infection/toxins, chronic inflammation of the pulp, cracked tooth, restorative procedures, pulpotomy and other factors are considered etiology agents. Early diagnosis and premature recognition, as well as ability of root canal procedures, are considered key for detention of internal root resorption process [3-5]. Clinically, "pink spots" can be found coronally due to the high vascularization. However, they are not always present and cannot be found easily [6]. If the resorption is not interrupted, color may change to gray or dark grey due to necrotic pulp [7] and the process can continue until perforation of the root. Oral radiographs can be used for diagnosis, but they contribute with limited information. Cone beam computed tomography (CBCT) proves to be more effective and reliable diagnostic method in recognizing resorptive lesions against digital intraoral radiography [8].

\section{Osteoclasts/Odontoclasts Activity}

Osteoclasts (OC) were originally described by the Swiss anatomist Albert von Kolliker (1817-1905). The formation of osteoclasts only takes place in the close vicinity of mineralized bone and, therefore, multinucleated osteoclasts never appear in the circulation [9]. OC are highly specialized cells and they are derived from hemopoietic cells of the monocyte-macrophage lineage [10].
Clastic cells are responsible for the resorption of mineralized matrix of hard tissues. Although firstly described as osteoclasts, they are able to resorb mineralized dental tissues, where they are called odontoclasts [11]. They are situated in dental pulp and periodontal ligament, sharing structural and cytochemical properties similarities with osteoclasts [12]. Multinuclear odontoclast cells involved in internal inflammatory root resorption are equivalent to bone resorbing osteoclasts. Formed through the fusion of multiple monocyte or macrophage /precursors, osteoclasts are giant, multinucleated cells and are the only cell type that can resorb bone $[7,13,14]$. They contain large numbers of mitochondria and acidic vacuoles that carry acid phosphatases and other lysosomal enzymes. The rough endoplasmic reticulum is scant, and the Golgi apparatus consists of few flattened cisternae around the nuclei [15].

\section{Ruffled Border}

The ruffled border acts as an exit site for protons, chloride ions, various enzymes and lysosomal proteases. During resorption, the first step on the resorptive process is acidification of bone surface. Dissolution of hydroxyapatite crystals results in exposure of the collagenous bone matrix [16]. Osteoclasts uses a vacuolar type proton ATPase (V-ATPase) which is inserted into the ruffled border plasma membrane supplies the large amounts of acid equivalents that are needed to break down the organic and inorganic portions of the bone matrix $[13,15]$. Following adhesion to bone matrix, OC form a unique ruffled border structure that is tightly sealed from the surrounding environment by a clear zone. Solubilization of hydroxyapatite crystals results in exposure of the collagenous bone matrix, then resorption lacunae are formed by collagen degradation, 
mediated mainly by lysosomal cysteine proteinases, cathepsins, secreted from OC [16]. Cathepsine K, a proteolytic enzyme, have been recognized as one of the significant proteinases in osteoclasts. Thus, seems to be the proteinase most active in these cells and play a key role in proteolysis in bone resorption [17]. The resorptive lacunae formed after osteoclast activity, might be occupied with granulation tissue [18].

\section{RANKL (Receptor Activator of NFkB Ligand) and OPG (Osteoprotegerin)}

Osteoclast genesis is mediated by a cascade of cytokines. Monocytes or osteoclast precursors that express RANK, a TNF receptor family member, recognize ODF (osteoclast differentiation factor)/RANKL (receptor activator of nuclear factor-kB ligand) through cell-to-cell interaction with osteoblasts/stromal cells, and differentiate into osteoclasts in presence of M-CSF (macrophage colony stimulating factor, also called CSF-1). M-CSF has been shown to be an essential factor for osteoclast formation in vivo and in vitro [19]. The molecules colony stimulating factor 1 (CSF-1) and monocyte chemotactic protein-1 (MCP-1) secreted by dental follicle cells are osteoclasts precursors. CSF-1 and MCP- 1 attract monocytes, which differentiate and fuse to form osteoclasts [12]. Osteoclast differentiation and activation was also reported, though cell-tocell contact. However, some studies demonstrated M-CSF has not any relationship with osteoclast activation induced by osteoblasts/ stromal cells. Thus, the effect of M-CSF is still controversial [20]. $\mathrm{OPG}$, which is secreted by osteoblasts and osteogenic stromal stem cells, inhibits bone resorption by binding to RANKL and preventing it from interacting with RANK [21].

\section{Removing Involved Tissues from Root Canal}

Root canal preparation provides antimicrobial effects through mechanical removal of biofilms. Engine-driven instrumentation is used more frequently by endodontists compared to hand instruments. Sometimes, cleaning and shaping is not easy to achieve due to the natural complexity of the pulpal space. Anatomic/ pathological factors could be considerably challenge in root canal shaping procedures. Using rotary instruments sculpts a round preparation, leaving areas of the root canal untouched. Another important factor in disinfection is irrigation. Cleaning and removing necrotic tissues/debrids from untouched areas by utilization of sodium hypochlorite is considered essential for desired results [22]. Bacterial populations inside of root canals should be ideally eliminated or at least significantly reduced [23]. Biofilms are the challenge to eradicate from canal anatomy and irregularities, if tooth is infected, they persist in the root canal spaces after debridement. Bacterial biofilms are formed by communities that are embedded in a self-produced matrix of extracellular polymeric substances (EPS) and are one of the most widely distributed and successful modes of life on Earth [24]. Irrigating solutions activity facilitate the killing and removal of microorganisms, dentine debris, necrotic and inflamed tissue [25]. However, bacterial persistence in root canals after cleaning and shaping was demostrated [23].
Previous experiences in Research and clinical revealed that sodium hypochlorite $(\mathrm{NaOCl})$ has several properties that contribute to effective chemo mechanical debridement of a root canal system and act as antimicrobial agent [26]. Even more, some authors revealed sodium hypochlorite was the most effective disinfectant against $\mathrm{C}$. Albicans in vitro, and both $5 \%$ and $0.5 \%$ concentrations showed complete killing in 30 seconds. Concentrations of $0.05 \%$ and $0.005 \%$ were not effective within 24 hours [27]. Ultrasonic techniques have shown satisfactory results for cleaning difficult areas such long resorption cavities and irregularities of the radicular canal. Smear layer produced during mechanical instrumentation, includes organic and inorganic substances such as pulp remnants, bacteria, odontoblasts processes and biofilms; arrest effectiveness of antimicrobial agents. Thus, smear layer packed into dentinal tubules, acts as physical barrier inhibiting effectiveness of the irrigants [27]. Using passive ultrasonic irrigation (PUI) for cleaning the canal system, it can remove more organic tissue, bacteria and dentine debrides. This procedure can be executed using a small file (size \#10 -\#20) oscillating deliberately inside the root canal to induce powerful acoustic microstreaming and can be effective in curved canals [28]. However, other studies have shown it may not prove to be so practical in narrow curved canals which have limited access to the apical zone. Microstreaming moves the solution in opposition to the root canal walls. Ultrasonic activation results more effective working altogether with irrigants when it's compared to the traditional needle alone [29]. Combination of $17 \%$ EDTA (ethylenediaminetetraacetic acid) and $\mathrm{NaOCl}$, is strongly recommended for effective elimination of smear layer from root canal system [30-35]. Using $\mathrm{Ca}(\mathrm{OH})_{2}$ (Calcium Hidroxide) as intracanal medication is suggested, due to its antimicrobial effects. However, some authors have questioned its efficacy against E. Faecalis and C. Albicans. Applications of $\mathrm{Ca}(\mathrm{OH})_{2}$ combined with Chlorhexidine seems to be more effective [36-39].

\section{Conclusion}

Internal root resorption is an unusual process. Early diagnosis and arresting are considered key for saving the tooth. Since there is not a definitive treatment for success, the effort should be emphasized in removing etiologic factors and tissues, using ultrasonic techniques, irrigants and intracanal medications as inhibitors and create a positive environment for the healing of surrounding tissues.

\section{References}

1. Gutmann JL (2017) Some historical musings on tooth/root resorption. J Istanb Univ Fac Dent 51(Suppl 1): S1-S9.

2. AAE (2016) Glossary of endodontic terms ( $9^{\text {th }}$ edn), USA.

3. Ne RF, Witherspoon DE, Gutmann JL (1999) Tooth resorption. Quintessence Int 30(1): 9-25.

4. Tronstad L (1988) Root resorption-etiology, terminology and clinical manifestations. Endod Dent Traumatol 4(6): 241-252.

5. Heithersay GS (1985) Clinical endodontic and surgical management of tooth and associated bone resorption. Int Ended J 18(2): 72-92. 
6. Ebeleseder KA, Kqiku L (2015) Arrest and calcification repair of internal root resorption with a novel treatment approach: Report of two cases. Dent Traumatol 31(47): 332-337.

7. Haapasalo M, Endal U (2006) Internal inflammatory root resorption: The unknown resorption of the tooth. Endodontic topics 14(1): 60-79.

8. Patel S, Dawood A, Wilson R, Horner K, Mannocci F (2009) The detection and management of root resorption lesions using intraoral radiography and cone beam computed tomography-an in vivo investigation. Int Endod J 42(9): 831-838.

9. Lerner UH (2000) Osteoclast formation and resorption. Matrix Biol 19(2): 107-120.

10. Suda T, Udagawa N, Nakamura I, Miyaura C, Takahashi N (1995) Modulation of osteoclast differentiation by local factors. Bone 17(Suppl 2): S87-S91.

11. Arana Chavez VE, Bradaschia Correa V (2009) Clastic cells: mineralized tissue resorption in health and disease. Int J Biochem Cell Biol 41(3): 446-450.

12. Wang Z, McCauley LK (2011) Osteoclasts and odontoclasts: Signaling pathways to development and disease. Oral Dis 17(2): 129-142.

13. Marino S, Logan JG, Mellis D, Capulli M (2014) Generation and culture of osteoclasts. Bonekey Rep 3: 570.

14. Sahara N, Toyoki A, Ashizawa Y, Deguchi T, Suzuki K (1996) Cytodifferentiation of the odontoclast prior to the shedding of human deciduous teeth: an ultrastructural and cytochemical study. Anat Rec 244(1): 33-49.

15. Robledo JG, Fernandez JJ (2018) Internal inflammatory root resorption Management with Mineral Trioxide Aggregate and Gutta-Percha. J Dent Oral Care Med 4(1): 105.

16. Sasaki T (2003) Differentiation and functions of osteoclasts and odontoclasts in mineralized tissue resorption. Microsc Res Tech 61(6): 483-495.

17. Kamiya T, Kobayashi Y, Kanaoka K, Nakashima T, Kato Y, et al. (1998) Fluorescence microscopic demonstration of cathepsin $\mathrm{K}$ activity as the major lysosomal cysteine proteinase in osteoclasts. J Bioch 123(4):752 759.

18. Yu CY, Abbott PV (2016) Responses of the pulp, peri radicular and soft tissues following trauma to the permanent teeth. Aust Dent J 61 Suppl 1: 39-58.

19. Kobayashi K, Takahashi N, Jimi E, Udagawa N, Takami M, et al. (2000) Tumor necrosis factor $\alpha$ stimulates osteoclast differentiation by a mechanism independent of the ODF/RANKL-RANK interaction. J Exp Med 191(2): 275-286.

20. Udagawa N, Takahashi N, Jimi E, Matsuzaki K, Tsurukai T, et al. (1999) Osteoblasts/stromal cells stimulate osteoclast activation through expression of osteoclast differentiation factor/RANKL but not macrophage colony-stimulating factor. Bone 25(5): 517-523.

21. Boyce BF, Xing L (2007) The RANKL/RANK/OPG pathway. Curr Osteoporos Rep 5(3): 98-104.

22. Haapasalo M, Shen Y, Wang Z, Gao Y (2014) Irrigation in endodontics. Br Dent J 216(6): 299-303.
23. Siqueira JF, Rôças IN (2008) Clinical implications and microbiology of bacterial persistence after treatment procedures. J Endod 34(11): 12911301.

24. Flemming HC, Wingender J, Szewzyk U, Steinberg P, Rice SA, et al. (2016) Biofilms: an emergent form of bacterial life. Nat Rev Microbiol 14(9): 563-575.

25. Haapasalo M, Shen Y, Qian W, Gao Y (2010) Irrigation in endodontics. Dental Clinics 54(2): 291-312.

26. Baumgartner JC, Cuenin PR (1992) Efficacy of several concentrations of sodium hypochlorite for root canal irrigation. J Endod 18(12): 605-612.

27. Waltimo TM, Ørstavik D, Siren EK, Haapasalo MP (1999) In vitro susceptibility of Candida albicans to four disinfectants and their combinations. Int Endod J 32(6): 421-429.

28. Van der Sluis LW, Versluis M, Wu MK, Wesselink PR (2007) Passive ultrasonic irrigation of the root canal: A review of the literature. Int Endod J 40(6): 415-426.

29. de Gregorio C, Estevez R, Cisneros R, Heilborn C, Cohenca N (2009) Effect of EDTA, sonic, and ultrasonic activation on the penetration of sodium hypochlorite into simulated lateral canals: An in vitro study. J Endod 35(6): 891-895.

30. Ballal NV, Jain I, Tay FR (2016) Evaluation of the smear layer removal and decalcification effect of QMix, maleic acid and EDTA on root canal dentine. J Dent 51: 62-68.

31. De Deus G, Paciornik S, Mauricio MH (2006) Evaluation of the effect of EDTA, EDTAC and citric acid on the microhardness of root dentine. Int Endod J 39(5): 401-407.

32. Kuah HG, Lui JN, Tseng PS, Chen NN (2009) The effect of EDTA with and without ultrasonics on removal of the smear layer. J Endod 35(3): 393396.

33. Kim D, Kim E (2014) Antimicrobial effect of calcium hydroxide as an intracanal medicament in root canal treatment: a literature review-Part I. In vitro studies. Restor Dent Endod 39(4): 241-252.

34. Domon T, Osanai M, Yasuda M, Seki E, Takahashi S, et al. (1997) Mononuclear odontoclast participation in tooth resorption: The distribution of nuclei in human odontoclasts. Anat Rec 249(4): 449-457.

35. Zheng Y, Chen M, He L, Marão HF, Sun DM, et al. (2015) Mesenchymal dental pulp cells attenuate dentin resorption in homeostasis. J Dent Res 94(6): 821-827

36. Ahmad M, Ford TR, Crum LA (1987) Ultrasonic debridement of root canals: Acoustic streaming and its possible role. J Endod 13(10): 490499.

37. Stenbeck G (2002) Formation and function of the ruffled border in osteoclasts. Semin Cell Dev Biol 13(4): 285-292.

38. Kishen A, Peters OA, Zehnder M, Diogenes AR, Nair MK (2016) Advances in endodontics: Potential applications in clinical practice. J Conserv Dent 19(3): 199-206.

39. Siqueira José F, Rôças IN, Ricucci D (2019) Internal tooth anatomy and root canal instrumentation. The Root Canal Anatomy in Permanent Dentition. Springer, pp. 277-302. 


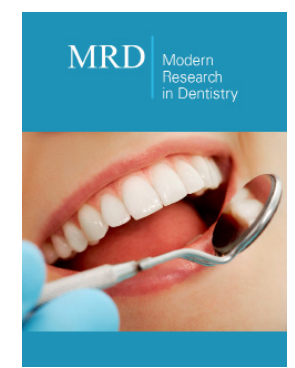

\section{Modern Research in Dentistry}

\section{Benefits of Publishing with us}

For possible submissions Click Here

Submit Article

- High-level peer review and editorial services

- Freely accessible online immediately upon publication

- Authors retain the copyright to their work

- Licensing it under a Creative Commons license

- Visibility through different online platforms 